\title{
Characterization of chemical compositions and bioactive compounds in juices from pomegranates ('Wonderful', 'Chaca' and 'Codpa') at different maturity stages
}

\author{
Mariela Labbé ${ }^{1 *}$, Pablo A. Ulloa ${ }^{2}$, Francisco López ${ }^{3}$, Carmen Sáenz ${ }^{1}$, Ālvaro Peña ${ }^{1}$,
} and Fernando N. Salazar ${ }^{2}$

\section{ABSTRACT}

In recent years, pomegranate (Punica granatum L.) fruit has gained popularity due to its functional properties. In this study, the effects of maturity on the chemical composition ( $\mathrm{pH}$, acidity and total soluble solids), total phenolic contents, anthocyanin contents and antioxidant capacities of pomegranate juices from three varieties (Wonderful, Chaca and Codpa) were assessed. The fruits were collected manually at three maturity stages (M1: unripe, M2: medium ripe, and M3: full ripe) from the Region de Coquimbo (Chile). Pomegranate juice was obtained from squeezed arils of fresh fruit. Results showed that chemical composition did not significantly differ according to the variety or maturity stage. Phenolic contents decreased during the final stage (M3) for 'Wonderful' and 'Codpa' (8\% and 29\%, respectively, from M2). Six main anthocyanin compounds (cyanidin 3,5-diglucoside, delphinidin 3,5-diglucoside, pelargonidin 3,5-diglucoside, cyanidin 3-glucoside, delphinidin 3-glucoside, and pelargonidin 3-glucoside) were detected in the three varieties. Significant differences in the anthocyanin content and antioxidant capacity were determined among different varieties and maturity stages. 'Codpa' pomegranate juice can be considered a good potential source of anthocyanin compounds (total content $715 \mathrm{mg} \mathrm{L}^{-1}$ ) with a high antioxidant capacity $\left(15.83 \mathrm{mmol}\right.$ Trolox $\left.\mathrm{L}^{-1}\right)$; the highest values for both parameters were observed in juice from fruits collected at the M2 stage. Principal component analysis allowed for differentiation of the pomegranate juices according to variety but not according to maturity stage.

Key words: Anthocyanin profile, antioxidant capacity, maturity stages, phenol content, pomegranate juice, Punica granatum.

${ }^{1}$ Universidad de Chile, Facultad de Ciencias Agronómicas, Casilla 1004, Av. Santa Rosa 11315, Santiago, Chile.

"Corresponding author (m.labbe.pino@gmail.com).

${ }^{2}$ Pontificia Universidad Católica de Valparaíso, Facultad de Ciencias Agronómicas y de los Alimentos, Waddington 716, Valparaíso, Chile. ${ }^{3}$ Universitat Rovira i Virgili, Facultat d’Enologia, Av. Països Catalans 26, 43007, Tarragona, España

Received: 17 June 2016.

Accepted: 3 October 2016.

doi:10.4067/S0718-58392016000400012

\section{INTRODUCTION}

Pomegranate (Punica granatum L.) derives from the Latin words pomus and granum, meaning a seeded or a granular apple, is one of the oldest edible fruits known to humankind. The edible part of a pomegranate fruit (arils) is mainly consumed directly or used for the preparation of juices and canned beverages, including alcoholic beverages, jellies, and jams, and it is also used for the flavoring and coloring of drinks. Over the last decade, the area used for pomegranate cultivation and production in Chile has increased significantly, passing of a cultivated area of 250 ha in 2007 to 1150 ha in 2015 (ODEPA, 2015). This increase is attributed to the rise in popularity of the pomegranate fruit in recent years due to the functional properties of its phenolic compounds, including phenolic acids, flavonoids (anthocyanins), condensed tannins (proanthocyanidins) and hydrolyzable tannins (ellagitannins and gallotannins) (Li et al., 2015; Mphahlele et al., 2016).

Phenolic compounds are bioactive compounds that comprise a diverse group of secondary metabolites present in higher plants. Anthocyanins are a group of natural pigments responsible for the red-blue colors of many fruits and vegetables. They are of interest because, along with their use as natural colorants, they also have important human health implications (Fischer et al., 2013b; Türkyilmaz, 2013; Radunic et al., 2015). Several studies have indicated that this family of flavonoids may have potential effects on reducing the incidences of cardiovascular diseases, cancer, hyperlipidaemia and other chronic diseases through the intake of anthocyanin-rich foods (Fischer et al., 2013b). Free radical scavenging and antioxidant activities have been suggested to play important roles in the prevention of free radical-related diseases, as well as in attenuation of the effects of ageing. Furthermore, anthocyanidins, which differ structurally from other flavonoids, except flavan-3-ol, and which do not have a carboxyl group in the $\mathrm{C}$-ring, prevent lipid peroxidation of cell or liposome membranes (Ben-Simhon et al., 2015). The most common anthocyanidins in higher plants are delphinidin, cyanidin, petunidin, pelargonidin, peonidin and malvidin. The glycosides of the three non-methylated anthocyanidins (delphinidin, cyanidin and pelargonidin) are the most abundant in nature. In this context, pomegranate is a rich source of 3-glucosides and 3,5-diglucosides of delphinidin, cyanidin and pelargonidin (Gómez-Caravaca et al., 2013; Radunic et al., 2015).

The anthocyanin content, antioxidant capacity and chemical composition may vary among fruits of similar types due to 
different external and internal factors, such as genetic and agronomic factors, light intensity, temperature, and processing method and storage conditions (Zaouay et al., 2012; Fernandes et al., 2015).

In this context, Radunic et al. (2015) evaluated the physical and chemical properties of eight pomegranate accessions from Croatia. They concluded that the properties (physical parameters, antioxidant activity, phenolic content and anthocyanin composition) of pomegranate fruit are affected by the genotype. Similar results were previously published by Schwartz et al. (2009), who studied the changes in chemical composition during fruit maturation in two Israeli commercial accessions. This knowledge could allow for determination of the optimal harvest time for obtaining the maximum nutritional properties. Other studies on the chemical composition of fruits have also found significant variations in growing locations (Mphahlele et al., 2014; 2016), phenolic compounds (Gil et al., 2000; Tzulker et al., 2007; Gómez-Caravaca et al., 2013; Fischer et al., 2013a; Li et al., 2015), sugars (Mphahlele et al., 2016), antioxidant activity (Borochov-Neori et al., 2009; Tehranifar et al., 2010; Zaouay et al., 2012), and mineral composition (Mirdehghan and Rahemi, 2007).

Alternatively, the maturity stage of pomegranate fruit is commonly assessed based on the external (skin) color, juice color and juice acidity (Gil et al., 1996; Schwartz et al., 2009; Mditshwa et al., 2013). The consumers' and processors' acceptability of pomegranate fruits depend on a combination of several quality attributes related to the physical, chemical and mechanical properties, including skin color, sugar content, acidity and flavor (Fischer et al., 2013a; Fernandes et al., 2015). Notably, blending traditional fruit juices with the so-called superfruits, such as pomegranate, can be another way to obtain new products with superfruit labels (Teixeira da Silva et al., 2013; López, 2014). Therefore, the main goal of this study was to determine the effects of maturity stages on the physicochemical parameters, anthocyanidin contents and antioxidant capacities of pomegranate juices from three different varieties.

\section{MATERIALS AND METHODS}

\section{Fruit collection}

Pomegranate fruits of three varieties, including 'Wonderful', 'Chaca' (UCH-CHA clone) and 'Codpa' (UCH-COD clone) obtained from the Vicuña locality (30¹'54' S, 7042'29" $\mathrm{W}$; semi-arid zone with annual conditions: minimum temperature $10{ }^{\circ} \mathrm{C}$, maximum temperature $17.5^{\circ} \mathrm{C}$ and average rainfall $67.8 \mathrm{~mm}$ ), Coquimbo Region, Chile, were analyzed (INE, 2015). Fruits were manually collected and transported to the laboratory. They were harvested in 2010 at three maturity stages (M1: unripe, M2: medium ripe, and M3: full ripe) based on subjective evaluation of the texture of fruit and skin color. The maturity stages were defined according to Al-Maiman and Ahmad (2002) with slight modifications. The M1 samples had a hard texture and green color; M2 samples had a firm texture and reddish color; and M3 samples had a cracked fruit without internal damage and reddish color. Twelve fruits of each maturity stages were picked (total 36 fruits for each variety). The peels were carefully removed, then the arils were manually extracted and were immediately processed. Pomegranate juice was obtained by squeezing the fruits $(n=12)$ using a juice extractor (3167, Oster, Boca Raton, Florida, USA). Then, juice samples of each variety and each maturity stage were frozen at $-20{ }^{\circ} \mathrm{C}$ until analyses. The yield of juice $\left(\mathrm{L} \mathrm{kg}^{-1}\right.$ arils) was determined for each sample type condition. All analytical assays were carried out in triplicate; only yield of juice was conducted once.

\section{Determination of $\mathrm{pH}$, total titratable acidity and total soluble solids}

The $\mathrm{pH}$ was measured at $20{ }^{\circ} \mathrm{C}$ using a $\mathrm{pH}$ meter (HI-210, Hanna Instruments, Woonsocket, Rhode Island, USA). Total titratable acidity (TTA) was determined potentiometrically using $0.1 \mathrm{M} \mathrm{NaOH}$ to the titration end-point of $\mathrm{pH} 8.2$, and values were expressed as percentage citric acid equivalents. Total soluble solids (TSS) values were measured at $20{ }^{\circ} \mathrm{C}$ with a refractometer (Abbe, A. Krüss Optronic, Hamburg, Germany) and were expressed as ${ }^{\circ}$ Brix. Moreover, maturity index (MI) was also calculated as the ratio of TSS to TTA, according to Nuncio-Jáuregui et al. (2015).

\section{Determination of total phenolic content and antioxidant capacity}

Total phenolic content (TFC) was determined using the colorimetric Folin-Ciocalteu method with slight modifications (Nuncio-Jáuregui et al., 2015). Briefly, $200 \mu \mathrm{L}$ diluted pomegranate juice was mixed with $800 \mu \mathrm{L}$ freshly prepared, diluted Folin Ciocalteu reagent $(1: 10, v / v)$ and 2 $\mathrm{mL} 7.5 \%$ sodium carbonate. The final mixture was diluted to $7 \mathrm{~mL}$ with deionized water. Mixtures were kept in the dark under ambient conditions for $2 \mathrm{~h}$ to allow for completion of the reaction. Absorbance at $765 \mathrm{~nm}$ was measured using a PG Instruments t70 UV/Vis spectrometer. Gallic acid was used as a standard, and the results were expressed as $\mathrm{mg}$ gallic acid equivalents (GAE) $100 \mathrm{~mL}^{-1}$ juice.

The total antioxidant capacity was measured by the ferric reducing antioxidant power (FRAP) assay, as described by Mphahlele et al. (2014), with slight modifications to adapt to a semi-microscale with a total volume of $1 \mathrm{~mL}$. Briefly, a portion of an aqueous $10 \mathrm{mM}$ solution TPTZ (2,4,6-tris(2pyridyl)-s-triazine) reagent in $40 \mathrm{mmol} \mathrm{L}^{-1} \mathrm{HCl}$ was mixed with the same volume of $20 \mathrm{mmol} \mathrm{L}^{-1} \mathrm{FeCl}_{3} \cdot 6 \mathrm{H}_{2} \mathrm{O}$ and a 10-fold higher volume of acetate buffer, $\mathrm{pH} 3.6$ (3.1 g sodium acetate and $16 \mathrm{~mL}$ acetic acid $\mathrm{L}^{-1}$ ). The mixture was then incubated at $37{ }^{\circ} \mathrm{C}$ for $10 \mathrm{~min}$. A portion $(900 \mu \mathrm{L})$ of the $\mathrm{Fe}^{3+}$-TPTZ mixture and $30 \mu \mathrm{L}$ of each sample (or standard or water for blank) were combined and diluted to $1000 \mu \mathrm{L}$ with deionized water and then incubated for $10 \mathrm{~min}$ before measuring absorbance at $593 \mathrm{~nm}$. FRAP values were calculated by comparing the absorption changes in the test 
mixtures relative to the values obtained using Trolox as a standard. Results were expressed as Trolox equivalent (TE) in $\mathrm{mmol} \mathrm{L}^{-1}$ juice.

\section{HPLC anthocyanin analysis}

Individual anthocyanin identification and quantification were performed using a liquid chromatograph (L-3000, Merck-Hitachi, Tokio, Japan) equipped with a UVVis L-7455 diode array detector (DAD) and L-7200 autoinjector, as described by Zaouay et al. (2012). The juice samples were filtered through a $0.45 \mu \mathrm{m}$ cellulose acetate membrane before injection into the HPLC system. A 20 $\mu \mathrm{L}$ aliquot of each sample was analyzed in a silica column $(25 \times 0.4 \mathrm{~cm} ; 5 \mu \mathrm{m}$ particle size; LiChrospher 250-4 RP18, Merck Millipore, Darmstadt, Germany) using the following solvents at room temperature: solvent A $(90 \%$ v/v formic acid) and solvent B (100\% acetonitrile). The compounds were eluted using a mobile phase of water/ formic acid $(95: 5, \mathrm{v} / \mathrm{v})$ (solvent $\mathrm{A}$ ) and HPLC-grade methanol (solvent B). Elution was performed at a flow rate of $1.1 \mathrm{~mL} \mathrm{~min}^{-1}$. The linear gradient started with $1 \%$ $\mathrm{B}$, keeping isocratic conditions for $5 \mathrm{~min}$ and reaching $20 \% \mathrm{~B}$ at $20 \mathrm{~min}, 40 \% \mathrm{~B}$ at $30 \mathrm{~min}, 95 \% \mathrm{~B}$ at $35 \mathrm{~min}$ and $1 \% \mathrm{~B}$ after $41 \mathrm{~min}$. Chromatograms were recorded at 520 $\mathrm{nm}$ on the DAD. Anthocyanin identity was assigned by comparison of their retention times with those of reference compounds. The quantified of anthocyanin were expressed as $\mathrm{mg} \mathrm{L}^{-1}$ malvidin-3-glucoside. The calibration curves at $520 \mathrm{~nm}$ were obtained by injection of different volumes of standard solutions under the same conditions as for the sample analyzed.

\section{Statistical analysis}

One-way ANOVA was conducted using SPSS version 17.0 (SPSS, Chicago, Illinois, USA, 2009) software to determine significant differences in chemical composition, anthocyanin contents and antioxidant capacities of pomegranate juices obtained from three varieties ('Wonderful', 'Codpa' and 'Chaca') and for three maturity stages (M1, M2, and M3). All data are reported as means (their respective standard deviations). Variables were analyzed with Student's t test (SPSS version 17.0) to check for significant differences $(p<0.05)$ between harvest dates. In addition, principal component analysis (PCA) was conducted using SIMCA-P 11.0 software (Umetrics AB, Malmö, Sweden).

\section{RESULTS AND DISCUSSION}

\section{Chemical compositions of pomegranate juices}

The results of chemical composition of pomegranate juices from the three cultivars at the three maturity stages (M1, M2, and M3) are presented in Table 1. The yield of juice per kilogram of arils showed a clear increase between maturity stages M1 and M2 and then a slight decrease (to less than 4.2\%) during M3. According to Supe and Saitwal (2016), these changes in yield of juice indicate that the fruit continuous to grow even after the optimum harvesting stage, due to translocation of sugars and water in the arils. With the rise in water content of arils, the percentage of seed has naturally declined in proportion to the juice content. The yields ranged from $50.1 \%$ to $62.6 \%$ (L juice $\mathrm{kg}^{-1}$ arils), and the highest yield values were obtained for 'Codpa'. Similarly, Al-Said et al. (2009) reported yields ranging from 57\%-67\% for 'Omani' pomegranate. In addition, Tehranifar et al. (2010) reported yields ranging from 27\%-47\% for Iranian pomegranate samples. These yields are similar to those observed by Zarei et al. (2011) for juice from 'Rabbab-e-Fars' pomegranate harvested at $140 \mathrm{~d}$ from the day of fruit set $(48.01 \%)$. The juice yield is influenced by cultivar and extraction method, with blender extraction generally yielding more juice compared to mechanical pressing (Radunic et al., 2015). During fruit maturity, peel and seeds percentage declined significantly, while the percentage of aril and juice (of whole fruit) increased significantly (Zarei et al., 2011).

With regard to TSS, all juice samples presented values higher than $12{ }^{\circ} \mathrm{Brix}$, the minimum value required for commercial use (Zaouay et al., 2012), with a range of 15.0 to $20.4^{\circ}$ Brix. For juices from 'Wonderful' (18.7 ${ }^{\circ}$ Brix) and 'Codpa' (20.4 ${ }^{\circ}$ Brix), the highest TSS values were obtained during the third (M3) and second stages (M2) of ripening, respectively. However, the TSS value of the juice from 'Codpa' decreased to $18.0^{\circ}$ Brix during the M3 ripening stage. Similar results were observed by Fernandes et al. (2015), who evaluated TSS in juice from pomegranates at four ripening stages (low, low-medium, medium, and medium-high). The TSS value was $18.6^{\circ}$ Brix during the medium stage, and it decreased to approximately $17.4^{\circ}$ Brix during the medium-high stage.

Table 1. Main physicochemical quality parameters of pomegranate juices from three varieties (Wonderful, Chaca and Codpa) at different maturity stages (M1: unripe, M2: medium ripe and M3: full ripe): total soluble solids (TSS), total titratable acidity (TTA), $\mathrm{pH}$, maturity index (MI), and ratio of juice to arils.

\begin{tabular}{|c|c|c|c|c|c|c|c|c|c|}
\hline \multirow[b]{2}{*}{ Parameter } & \multicolumn{3}{|c|}{ Wonderful } & \multicolumn{3}{|c|}{ Chaca } & \multicolumn{3}{|c|}{ Codpa } \\
\hline & M1 & M2 & M3 & M1 & M2 & M3 & M1 & M2 & M3 \\
\hline TSS, ${ }^{\circ}$ Brix & $18.2 \pm 0.6 \mathrm{Bb}$ & $17.0 \pm 0.0 \mathrm{Aa}$ & $18.7 \pm 0.3 \mathrm{Bb}$ & $15 \pm 0 \mathrm{Aa}$ & $18.2 \pm 0.3 \mathrm{Bb}$ & $18.4 \pm 0.1 \mathrm{Bb}$ & $17.7 \pm 0.3 \mathrm{Ab}$ & $20.4 \pm 0.2 \mathrm{Bc}$ & $18 \pm 0 \mathrm{Aa}$ \\
\hline TTA, $\%$ citric acid & $1.1 \pm 0.08 \mathrm{Ab}$ & $1.2 \pm 0.02 \mathrm{Ba}$ & $1.04 \pm 0.01 \mathrm{Ab}$ & $1.09 \pm 0.03 \mathrm{Ab}$ & $1.13 \pm 0.16 \mathrm{Aa}$ & $0.92 \pm 0.01 \mathrm{Aa}$ & $0.95 \pm 0.01 \mathrm{Aa}$ & $1.32 \pm 0.01 \mathrm{Ca}$ & $1.04 \pm 0.01 \mathrm{Bb}$ \\
\hline $\mathrm{pH}$ & $3.49 \pm 0.06 \mathrm{Ba}$ & $3.26 \pm 0.02 \mathrm{Aa}$ & $3.61 \pm 0.01 \mathrm{Ca}$ & $3.6 \pm 0 \mathrm{Bb}$ & $3.46 \pm 0.02 \mathrm{Ab}$ & $3.68 \pm 0.02 \mathrm{Cb}$ & $3.68 \pm 0.02 \mathrm{Bc}$ & $3.47 \pm 0.01 \mathrm{Ab}$ & $3.66 \pm 0.02 \mathrm{Bb}$ \\
\hline MI & $16.5 \pm 1.6 \mathrm{Bb}$ & $14.1 \pm 0.2 \mathrm{Aa}$ & $17.9 \pm 0.2 \mathrm{Bb}$ & $13.8 \pm 0.3 \mathrm{Aa}$ & $16.3 \pm 2.3 \mathrm{Ba}$ & $20.1 \pm 0 \mathrm{Bc}$ & $18.5 \pm 0.4 \mathrm{Cc}$ & $15.4 \pm 0.2 \mathrm{Aa}$ & $17.3 \pm 0.1 \mathrm{Bb}$ \\
\hline Ratio, L juice $\mathrm{kg}^{-1}$ arils & 0.50 & 0.58 & 0.56 & 0.54 & 0.60 & 0.59 & 0.55 & 0.63 & 0.60 \\
\hline
\end{tabular}

For each maturity stages, means within the same row followed by a different uppercase letter are significantly different $(p<0.05)$.

For each variety, means within the same row followed by a different lower-case letter are significantly different $(p<0.05)$. 
The results for total titratable acidity (TTA) and $\mathrm{pH}$ showed a clear relation. The TTA values ranged from $0.92 \%$ to $1.32 \%$ citric acid. Although this value usually tends to continuously decrease during ripening (Al-Maiman and Ahmad, 2002; Fawole and Opara, 2013), in our study of three cultivars, TTA was higher during M2. Obviously, $\mathrm{pH}$ values were lower at this stage compared with those at the other stages (with $\mathrm{pH}$ values ranging from 3.26 to 3.47). However, at the M2 sampling point, no significant differences in TTA were observed among cultivars; 'Codpa' $(0.95 \%$ citric acid) and 'Chaca' $(0.92 \%$ citric acid) had lower acidity levels at M1 and M3, and 'Wonderful' had the lowest $\mathrm{pH}$ across all ripening stages. The low TTA levels could be explained by changes in the relative amounts of malic and citric acids, which have previously been identified as the major acids in pomegranate fruits (Gil et al., 1996).

According to previous studies published by Al-Maiman and Ahmad (2002), the $\mathrm{pH}$ of juice from the 'Taifi' increases with maturity, reaching a maximum $\mathrm{pH}$ of 3.57 at the fullripe stage. Further, Shwartz et al. (2009) reported that in 'Rosh-Hapered' and 'Wonderful' pomegranates, TSS and $\mathrm{pH}$ increased and acidity decreased from the unripe stage (M1) to the full ripe stage (M3). However, these changes were significant only in the pomegranate juice from 'Chaca' in this study. The differences in results between our study and previous studies may be due to the use of different harvest criteria and pomegranate types and to the various years and regions in which the fruits were grown, which may have affected the processes that occurred during the maturation stages (Fawole and Opara, 2013; Fernandes et al., 2015).

The MI is related to the taste and flavor of pomegranate, and some authors have used it to classify pomegranate cultivars (Tehranifar et al., 2010). This classification has been optimized for Spanish cultivars as follows: $\mathrm{MI}=5-7$ for sour; $\mathrm{MI}=17-24$ for sour-sweet; and MI = 31-98 for sweet cultivars (Martínez et al., 2006). The MI remained stable for all samples, ranging from 13.8-20.1. Only 'Chaca' exhibited a clear increase in this parameter with increasing maturity. However, the other two cultivars showed the lowest MIs for samples at M2 stage. According to the classification established for Spanish cultivars, all samples could be considered to be sour-sweet. Chace et al. (1981) have reported that pomegranates are suitable for fresh market when their acidity content is lower than $1.8 \%$ and their MI is between 7 and 12 and that when the MI ranges from 11 to 16, pomegranates are quite tasty. According to these criteria, pomegranate samples analyzed in this study were suitable for fresh consumption.

The harvesting time of pomegranate fruit is an aspect of particular importance because early harvesting may inhibit the development of the quality characteristics (e.g., color, flavor and aroma), while late harvesting may result in fruits with a reduced shelf life and increased sensitivity to disease (Fernandes et al., 2015).

\section{Total phenolic content of pomegranate juice}

Phenolic compounds in fruits and vegetables have important contributions to sensory attributes, as well as potential health benefits (Radunic et al., 2015). Notably, loss of astringency is a desirable change that occurs during maturation and ripening of pomegranate fruits that is primarily due to decreases in the levels of phenolic compounds during maturation (Kulkarni and Aradhya, 2005; Fawole and Opara, 2013). Figure 1a shows total phenolic content (TPC) in pomegranate juices from the fruits harvested at different maturity stages. The results obtained for three cultivar samples showed that the highest TPC was present in juice from fruits harvested at M2 stage (range $130-227 \mathrm{mg} \mathrm{GAE} 100 \mathrm{~mL}^{-1}$ ) and that it significantly decreased with advancing maturity (M3). Only 'Chaca' exhibited an increase in this value with advancing ripening stage $\left(130 \mathrm{mg}\right.$ GAE $100 \mathrm{~mL}^{-1}$ for $\mathrm{M} 2$ and 213 mg GAE $100 \mathrm{~mL}^{-1}$ for M3). Similar results were observed

Figure 1. Total phenolic content (TPC, a) and antioxidant capacity (b) of pomegranate juices from three varieties (Wonderful, Chaca and Codpa) harvested at different maturity stages (M1: unripe, M2: medium ripe and M3: full ripe).
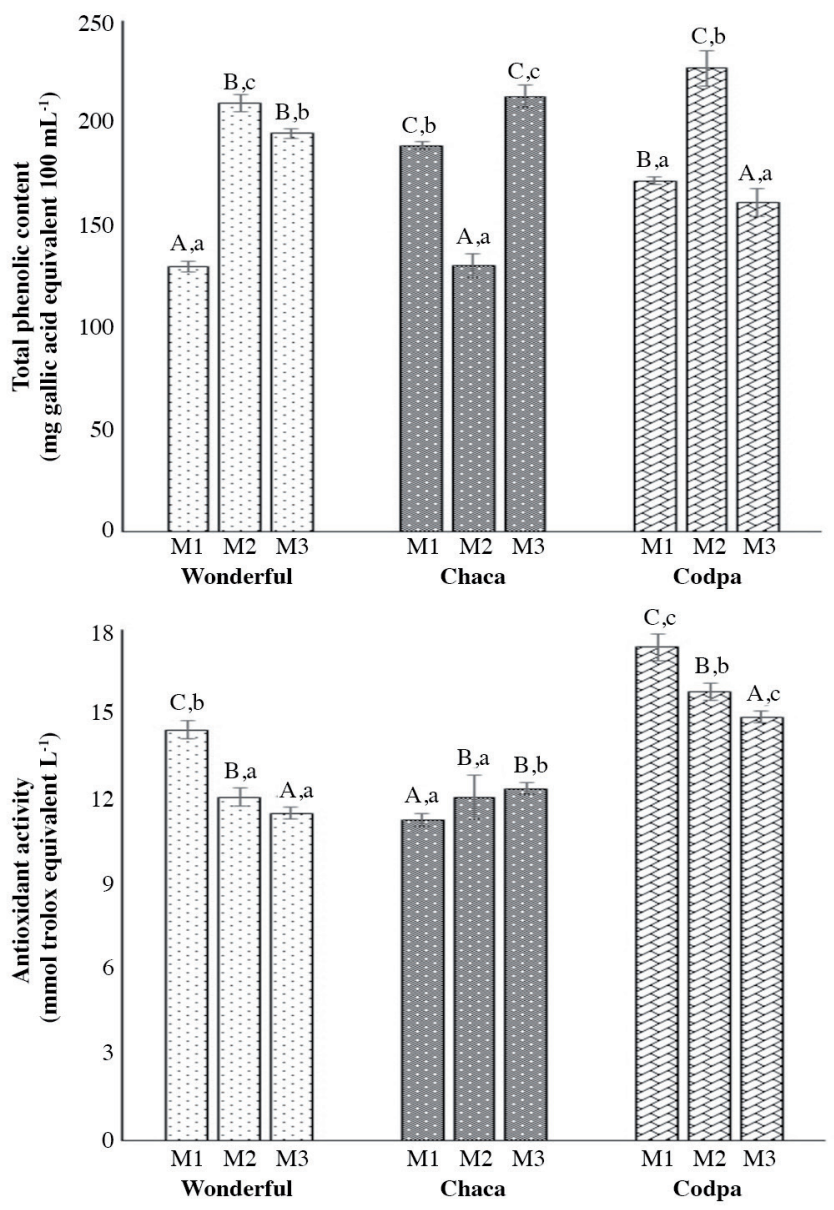

For each maturity stages, means within the same row followed by a different uppercase letter are significantly different $(p<0.05)$.

For each variety, means within the same row followed by a different lowercase letter are significantly different $(p<0.05)$. 
by Kulkarni and Aradhya (2005) in pomegranate samples from 'Ganesh' at different developmental stages. This group found that TPC values decreased by approximately $74 \%$ during fruit growth and maturation. In addition, Weerakkody et al. (2010) found that TPC decreased by approximately $50 \%$ in juice from 'Wonderful' in Australia during fruit development. The content varied from 1710 mg GAE L ${ }^{-1}$ (immature fruit) to $790 \mathrm{mg} \mathrm{GAE} \mathrm{L}^{-1}$ (mature fruit). The decreased TPCs in our samples ('Wonderful' and 'Codpa') could be explained by oxidation of phenolic compounds due to the presence of polyphenol oxidase, which characterizes these stages of maturity (Shwartz et al., 2009; Zarei et al., 2011). Alternatively, it is possible that some phenolics were used as substrates for enzymatic browning (Kulkarni and Aradhya, 2005), with the presence of this enzyme being more significant in these two varieties, as demonstrated by the lower TPC values (for M3, values of 191 and $161 \mathrm{mg}$ GAE $100 \mathrm{~mL}^{-1}$; respectively). Several authors have demonstrated that TPC is reduced in pomegranate juice during ripening and maturation and the antioxidant metabolites changes in response to abiotic stress (Mirdehghan and Rahemi, 2007; Shwartz et al., 2009; Weerakkody et al., 2010; Zarei et al., 2011).

Zaouay et al. (2012) reported similar TPCs in juice from pomegranates grown in Tunisia, demonstrating

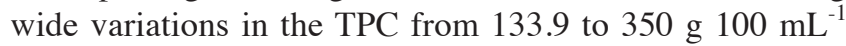
juice. These results indicated that this pomegranate juice displayed the highest TPC. Most of the phenolic compounds present in the pomegranate peel are passed into the juice during pressing (Gözlekci et al., 2011). On the other hand, the phenolic concentration and composition in pomegranate fruits are cultivar-dependent; the most abundant components are anthocyanins, catechins, ellagic tannins, and gallic and ellagic acids. In addition, the season of development and ripening (Borochov-Neori et al., 2009) and genetic variability lead to variations in the biosynthesis of phenolic metabolites in these cultivars (Tehranifar et al., 2010).

\section{Antioxidant capacity of pomegranate juice}

The beneficial effects attributed to pomegranate fruit consumption are related to antioxidant activity. Figure $1 \mathrm{~b}$ shows the antioxidant capacities of pomegranate juices from fruits harvested at different maturity stages, as determined using the FRAP method. 'Wonderful' and 'Codpa' exhibited clear decreases in the antioxidant capacities during ripening (between 14\% and 20\%) from M1 to M3. However, 'Chaca' showed the lowest antioxidant capacity during M1, although in this case, differences between maturity stages were less substantial. Similar results were obtained by Kulkarni and Aradhya (2005), who examined pomegranate arils of 'Ganesh' and showed that the antioxidant activity was reduced to nearly $13 \%$ from 20 to $60 \mathrm{~d}$ of fruit development. This reduction was due to decreases in the phenolic content (74\%) and ascorbic acid concentration (80\%). Shwartz et al. (2009) reported that the antioxidant activity was significantly reduced over $10 \mathrm{wk}$ of maturation from 10.3 to $7.8 \mathrm{mM}$ in a landrace of 'Rosh-Hapered'. However, only a slight reduction was observed in a landrace of 'Wonderful' representing the late-season-ripening pomegranate. Similar results were reported by Weerakkody et al. (2010), who assessed 'Wonderful' during ripening for two seasons and found that the total antioxidant activity (FRAP) during the first year decreased with fruit maturation (35.7 to $11.6 \mathrm{mM}$ $\mathrm{Fe}^{+2} \mathrm{~L}^{-1}$ ), while the changes were less pronounced during the second season. Further, Kulkarni and Aradhya (2005) observed a reduction of approximately $13 \%$ in antioxidant activity during pomegranate aril ripening due to reduced concentrations of total phenolics and ascorbic acid.

The decreased antioxidant activity was concomitant with a decrease in the TPC from M1 to M3; this decreased activity has been attributed to presence of phenolic compounds in pomegranate and many other fruits (Zarei et al., 2011; Mphahlele et al., 2014; Fernandes et al., 2015).

In our study, the highest antioxidant capacities for the three maturity stages were observed in the pomegranate juice from 'Codpa' $\left(17.4,15.8\right.$, and 14.9 mmol TE L ${ }^{-1}$ for M1, M2 and M3; respectively), followed by those from 'Wonderful' and 'Chaca'. These values are in the range of those observed by other authors in pomegranate juices (Shwartz et al., 2009). These results could be partly explained by the higher anthocyanin content in 'Codpa'. However, although several authors have demonstrated an association between anthocyanin content and antioxidant capacity (Schwartz et al., 2009), other authors have also suggested the importance of phenolic and ascorbic acids levels to the seasonal changes in total antioxidant activity and TPC (Kulkarni and Aradhya, 2005). Accordingly, Gil et al. (2000) have reported that main antioxidant compounds in pomegranate juice are hydrolysable tannins, while anthocyanins and ellagic acid derivatives also contribute to the total antioxidant capacity.

\section{Anthocyanin contents of pomegranate juices}

One of the most important quality characteristics of pomegranate is the red pigmentation of seeds and juice, which is affected by the anthocyanin concentration and the chemical structures of the individual anthocyanins (Borochov-Neori et al., 2011; Ben-Simhon et al., 2015). Anthocyanin analysis by HPLC detected six main compounds in the three analyzed samples: cyanidin 3,5-diglucoside (Cy3,5); delphinidin 3,5-diglucoside (Dp3,5); pelargonidin 3,5-diglucoside $(\mathrm{Pg} 3,5)$; cyanidin 3-glucoside (Cy3); delphinidin 3-glucoside (Dp3); and pelargonidin 3-glucoside $(\mathrm{Pg} 3)$. The total anthocyanin content was calculated by summation of the contents of the individual anthocyanins. The anthocyanin content results are presented in Table 2. The total contents were higher at M2 for all pomegranate cultivars, although the differences were not significant for 'Wonderful'. With regard to differences among the varieties, total anthocyanin contents were higher in the juices from 'Codpa' compared with those from the other two varieties across the three maturity stages; 'Codpa' samples showed values ranging from 65.5 to $71.5 \mathrm{mg} 100$ $\mathrm{mL}^{-1}$. These values were significantly higher than those in 
Table 2. Anthocyanin profiles of pomegranate juices from three varieties (Wonderful, Chaca and Codpa) at different maturity stages (M1: unripe, M2: medium ripe and M3: full ripe).

\begin{tabular}{|c|c|c|c|c|c|c|c|c|c|c|}
\hline \multirow{2}{*}{$\begin{array}{l}\text { Compound } \\
\text { (mg malvidin-3- } \\
\text { glucoside } 100 \mathrm{~mL}^{-1} \text { ) }\end{array}$} & \multirow{2}{*}{$\underset{(\mathrm{min})}{\mathrm{t}_{\mathrm{R}}}$} & \multicolumn{3}{|c|}{ Wonderful } & \multicolumn{3}{|c|}{ Chaca } & \multicolumn{3}{|c|}{ Codpa } \\
\hline & & M1 & M2 & M3 & M1 & M2 & M3 & M1 & M2 & M3 \\
\hline $\begin{array}{l}\text { Delphinidin 3,5-diglucoside } \\
\text { (Dp3,5) } \\
\text { Cyanidin 3,5-diglucoside }\end{array}$ & 6.9 & $18.9 \pm 1.1 \mathrm{Bb}$ & $17.8 \pm 1.5 \mathrm{Bb}$ & $13.5 \pm 1.2 \mathrm{Aa}$ & $11.5 \pm 1.0 \mathrm{Aa}$ & $11.7 \pm 1.4 \mathrm{Aa}$ & $11.7 \pm 1.0 \mathrm{Aa}$ & $17.5 \pm 1.1 \mathrm{Ab}$ & $19.3 \pm 0.7 \mathrm{Ab}$ & $17.5 \pm 1.2 \mathrm{Ab}$ \\
\hline $\begin{array}{l}(\text { Cy3,5) } \\
\text { Pelargonidin 3,5-diglucosido }\end{array}$ & 7.7 & $28.7 \pm 1.1 \mathrm{Ab}$ & $32.6 \pm 2.1 \mathrm{ABb}$ & $36.4 \pm 2.4 \mathrm{Bb}$ & $18.9 \pm 1.1 \mathrm{Aa}$ & $24.4 \pm 1.2 \mathrm{Ba}$ & $23.8 \pm 0.7 \mathrm{Ba}$ & $32.1 \pm 1.4 \mathrm{Ac}$ & $35.2 \pm 1.1 \mathrm{Ab}$ & $34.7 \pm 1.5 \mathrm{Ab}$ \\
\hline $\begin{array}{l}(\mathrm{Pg} 3,5) \\
\text { Delphinidin 3-glucoside }\end{array}$ & 8.2 & $0.7 \pm 0.01 \mathrm{Ab}$ & $0.8 \pm 0.01 \mathrm{Ab}$ & $0.7 \pm 0.02 \mathrm{Ab}$ & $0.3 \pm 0.003 \mathrm{Ba}$ & $0.23 \pm 0.02 \mathrm{Aa}$ & $0.21 \pm 0.02 \mathrm{Aa}$ & $1.6 \pm 0.002 \mathrm{Ac}$ & c $2.5 \pm 0.03 \mathrm{Cc}$ & $1.9 \pm 0.06 \mathrm{Bc}$ \\
\hline $\begin{array}{l}\text { (Dp3) } \\
\text { Cyanidin 3-glucoside }\end{array}$ & 8.7 & $1.9 \pm 0.1 \mathrm{Bb}$ & $2.0 \pm 0.01 \mathrm{Bb}$ & $1.4 \pm 0.06 \mathrm{Ab}$ & $1.0 \pm 0.05 \mathrm{Aa}$ & $1.2 \pm 0.1 \mathrm{Ba}$ & $1.0 \pm 0.04 \mathrm{Aa}$ & $2.3 \pm 0.1 \mathrm{Ac}$ & $2.5 \pm 0.06 \mathrm{Bc}$ & $2.5 \pm 0.06 \mathrm{Bc}$ \\
\hline $\begin{array}{l}\text { (Cy3) } \\
\text { Pelargonidin 3-glucoside }\end{array}$ & 9.5 & $10.2 \pm 0.7 \mathrm{Ab}$ & $11.7 \pm 0.8 \mathrm{Ab}$ & $10.6 \pm 0.9 \mathrm{Ab}$ & $7.1 \pm 0.5 \mathrm{Ba}$ & $8.1 \pm 0.4 \mathrm{Ca}$ & $6.0 \pm 0.4 \mathrm{Aa}$ & $11.8 \pm 0.2 \mathrm{Ac}$ & $11.6 \pm 1.0 \mathrm{Ab}$ & $11.8 \pm 1.3 \mathrm{Ab}$ \\
\hline $\begin{array}{l}(\mathrm{Pg} 3) \\
\text { Total anthocyanin content }\end{array}$ & 11.2 & $\begin{array}{l}0.4 \pm 0.01 \mathrm{Bc} \\
60.9 \pm 0.6 \mathrm{Ab}\end{array}$ & $\begin{aligned} 0.6 & \pm 0.01 \mathrm{Cc} \\
65.4 & \pm 0.9 \mathrm{Ab}\end{aligned}$ & $\begin{aligned} 0.3 & \pm 0.02 \mathrm{Ab} \\
62.8 & \pm 3.7 \mathrm{Ab}\end{aligned}$ & $\begin{array}{l}0.2 \pm 0.01 \mathrm{Aa} \\
39.0 \pm 0.5 \mathrm{Aa}\end{array}$ & $\begin{aligned} 0.3 & \pm 0.01 \mathrm{Ca} \\
46.0 & \pm 1.7 \mathrm{Ca}\end{aligned}$ & $\begin{aligned} & 0.2 \pm 0.01 \mathrm{Ba} \\
& 43.0 \pm 0.6 \mathrm{Ba}\end{aligned}$ & $\begin{array}{l}0.28 \pm 0.00 \mathrm{Ab} \\
65.5 \pm 2.2 \mathrm{Ac}\end{array}$ & $\begin{array}{r}4.3 \pm 0.1 \mathrm{Cb} \\
71.5 \pm 2.6 \mathrm{Bc}\end{array}$ & $\begin{aligned} 0.4 & \pm 0.002 \mathrm{Bc} \\
68.7 & \pm 1.0 \mathrm{ABc}\end{aligned}$ \\
\hline
\end{tabular}

For each maturity stages, means within the same row followed by a different uppercase letter are significantly different $(p<0.05)$.

For each variety, means within the same row followed by a different lower-case letter are significantly different $(p<0.05)$.

$\mathrm{t}_{\mathrm{R}}$ : Retention time $(\mathrm{min})$.

the juices from 'Wonderful' (60.9 to $\left.65.4 \mathrm{mg} 100 \mathrm{~mL}^{-1}\right)$ and 'Chaca' (39.0 to $46.0 \mathrm{mg} 100 \mathrm{~mL}^{-1}$ ). These values are higher than those reported by Zaouay et al. (2012) for Tunisian pomegranate, in which the anthocyanin contents were found to range from 5.10 to $49 \mathrm{mg} 100 \mathrm{~mL}^{-1}$. Delphinidin 3,5-diglucoside was the predominant anthocyanin in all cultivars $\left(40.7 \mathrm{mg} 100 \mathrm{~mL}^{-1}\right)$.

Similar results were published by Sepúlveda et al. (2010) regarding the anthocyanin content in Chilean pomegranate juice, which reached between 170 and $1342 \mathrm{mg}$ cyanidin3 -glucoside $\mathrm{L}^{-1}$. Moreover, this group determined the anthocyanin profiles in the juice samples and identified the same six anthocyanins (Cy3,5; Dp 3,5; Pg 3,5; Cy3; Dp3 and Pg3) as those detected in our study, but at lower concentrations. The main anthocyanin present at the highest concentrations in the three varieties during the different maturity stages was cyanidin 3,5-diglucoside (18.9-36.4 mg $100 \mathrm{~mL}^{-1}$ ), which is responsible for red pigmentation (BenSimhon et al., 2015). These results are consistent with those obtained by Hasnaoui et al. (2011), who reported that Cy3,5 was a major anthocyanin in Tunisian pomegranate juice. On the other hand, the anthocyanin present at the lowest concentration was pelargonidin 3-glucoside $(0.2-4.3 \mathrm{mg}$ $100 \mathrm{~mL}^{-1}$ ), which is responsible for orange pigmentation (Ben-Simhon et al., 2015). A similar anthocyanin profile was observed in Turkey pomegranate juice, as reported by Türkyilmaz (2013), who found six different anthocyanins (3-glucoside and 3,5-diglucosides of pelargonidin, cyaniding and delphinidin), with Cy $3,5\left(170 \mathrm{mg} \mathrm{L}^{-1}\right)$ and $\mathrm{Cy} 3\left(150 \mathrm{mg} \mathrm{L}^{-1}\right)$ being present at the highest concentrations in Izmir 1513 samples.

The anthocyanin content decreased by approximately $4.5 \%$ from M2 to the final stage M3 for all varieties; this finding can be attributed to degradation of pomegranate fruit exposed to high temperatures due to increased oxidative stress, thereby inducing the activity of peroxidase, which operates at an ideal temperature between 17 and $26{ }^{\circ} \mathrm{C}$ (Fischer et al., 2013b; Mphahlele et al., 2014).

\section{Principal component analysis}

Principal component analysis (PCA) was performed to further elucidate the effects on the varieties and maturity stages on pomegranate juice quality characteristics. This analysis has been previously used by some authors to characterize pomegranate juice (Schwartz et al., 2009; Mphahlele et al., 2014), antioxidant activity (Zaouay et al., 2012), varieties (Radunic et al., 2015), and bioactive compounds (Nuncio-Jáuregui et al., 2015). The total variability was described using 11 factors (TSS, pH, TTA, FRAP, TPC, and anthocyanin profile), with the two first principal components explaining $73.08 \%$ of variation in the values. PC1 was responsible for $53.6 \%$ of the total variation, while PC2 contributed $19.4 \%$. A plot of samples in the plane defined by PCA is shown in Figure 2. Considering PC1 values, 'Chaca' samples appeared on the left side of the plane, 'Codpa' samples were located on the right side, and 'Wonderful' samples appeared in the middle. In PC1, the separation among varieties was attributed to the anthocyanin profiles and was mainly due differences in anthocyanin contents among the varieties. Regarding the PC2 values, a clear separation was observed for 'Codpa' and 'Wonderful' according to $\mathrm{pH}$. However, it was not possible to reach a clear conclusion because the order of PC2 values was different for each cultivar. These results demonstrated that the pomegranate juices from the different varieties could be successfully distinguished based on their anthocyanin profiles. On the other hand, they could not be distinguished according to the maturity stage.

\section{CONCLUSIONS}

The present study showed that the chemical composition, total phenolic content, antioxidant capacity and anthocyanin profile do not significantly differ across the different stages of maturity (unripe, medium ripe, and full ripe) in pomegranate juice. However, significant differences were observed among the different pomegranate cultivars 
Figure 2. Plot of principal component analysis (PCA) of pomegranate juices from three varieties (Wonderful, Chaca and Codpa) harvested at different maturity stages.

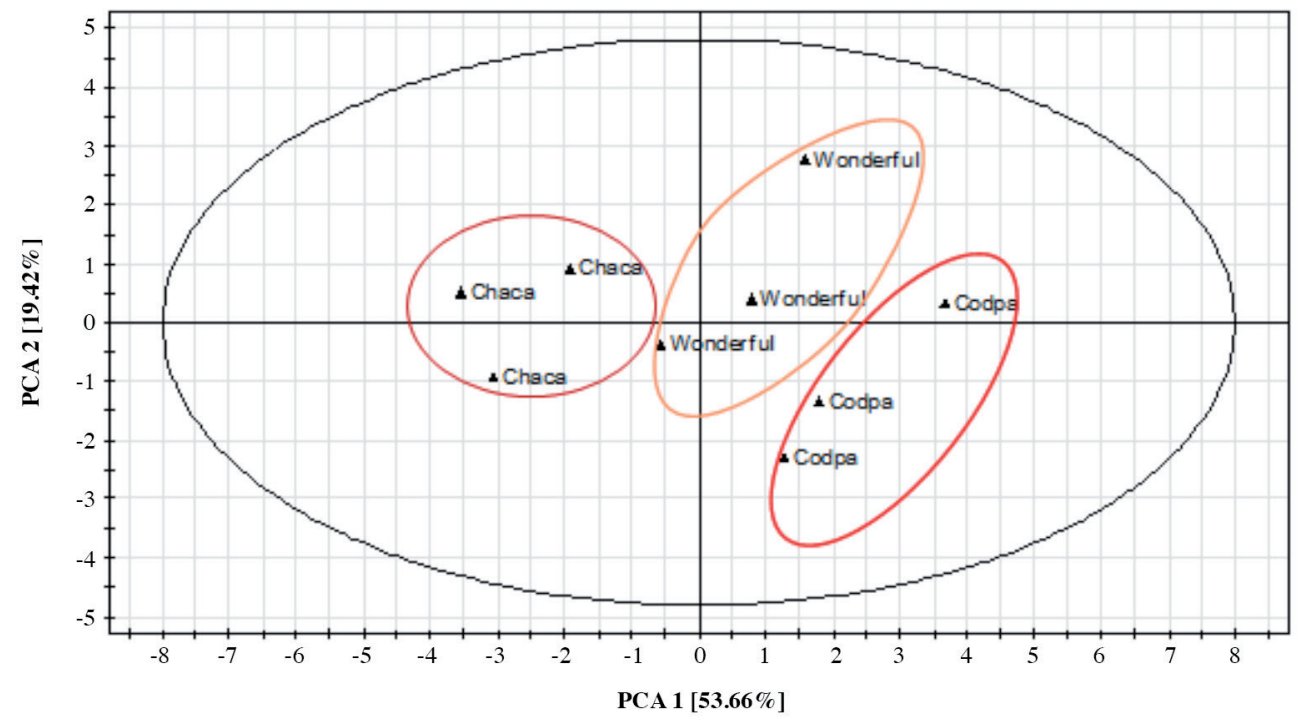

assessed (Wonderful, Chaca and Codpa). Specifically, 'Codpa' may be considered a potential source of bioactive compounds (phenolic and anthocyanins) with a high antioxidant capacity. Cyanidin 3,5-diglucoside was the major anthocyanin in all three pomegranate varieties, followed by delphinidin 3,5-diglucoside, cyanidin 3-glucoside, delphinidin 3-glucoside, pelargonidin 3,5-diglucoside and pelargonidin 3-glucoside. Principal component analysis showed that the pomegranate varieties were mainly distinguishable according to the anthocyanin profile and $\mathrm{pH}$. These results contribute to current knowledge about their chemical composition, phenolic contents, anthocyanin profiles and antioxidant activities pomegranate juices from different varieties. This information may be useful to producers, breeders and processors.

\section{ACKNOWLEDGEMENTS}

The authors are grateful to the FONDECYT Project $\mathrm{N}^{\circ}$ 3090006 for their financial support of this work. The authors are indebted to Dr. Nicolas Franck for providing the pomegranate fruits through INNOVA-CORFO Project $\mathrm{N}^{\circ} 07$ CT9PZT-32.

\section{REFERENCES}

Al-Maiman, S.A., and D. Ahmad. 2002. Changes in physical and chemical properties during pomegranate (Punica granatum L.) fruit maturation. Food Chemistry 76:437-441. doi:10.1016/ S0308-8146(01)00301-6.

Al-Said, F.A., L.U. Opara, and R.A. Al-Yahyai. 2009. Physicochemical and textural quality attributes of pomegranate cultivars (Punica granatum L.) grown in the sultanate of Oman. Journal of Food Engineering 90:129-134. doi:10.1016/ j.jfoodeng.2008.06.012.
Ben-Simhon, Z., S. Judeinstein, T. Trainin, R. Harel-Beja, I. Bar-Ya'akov, H. Borochov-Neori, et al. 2015. A "White" anthocyanin-less pomegranate (Punica granatum L.) caused by an insertion in the coding region of the Leucoanthocyanidin Dioxygenase (LDOX; ANS) gene. PLoS ONE 10:e142777. doi:10.1371/journal.pone.0142777.

Borochov-Neori, H., S. Judeinstein, M. Harari, I. Bar-Ya'akov, B.S. Patil, S. Lurie, et al. 2011. Climate effects on anthocyanin accumulation and composition in the pomegranate (Punica granatum L.) fruit arils. Journal of Agricultural and Food Chemistry 59:5325-5334. doi:10.1021/jf2003688.

Borochov-Neori, H., S. Judeinstein, E. Tripler, M. Harari, A. Greenberg, I. Shomer, et al. 2009. Seasonal and cultivar variations in antioxidant and sensory quality of pomegranate (Punica granatum L.) fruit. Journal of Food Composition and Analysis 22:189-195. doi:10.1016/j.jfca.2008.10.011.

Chace, E.M., G. Church, and H. Poore. 1981. The wonderful variety of pomegranate. USDA Circular $98.15 \mathrm{p}$.

Fawole, O.A., and U.L. Opara. 2013. Developmental changes in maturity indices of pomegranate fruit: A descriptive review. Scientia Horticulturae 159:152-161. doi:10.1016/ j.scienta.2013.05.016.

Fernandes, L., J.A. Prereira, I. Lopéz-Cortés, D.M. Salazar, and E.C. Ramalhosa. 2015. Physicochemical changes and antioxidant activity of juice skin, pellicle and seed of pomegranate (cv. Mollar de Elche) at different stages of ripening. Food Technology and Biotechnology 54:397-406. doi:10.17113/ftb.53.04.15.3884.

Fischer, U.A., R. Carle, and D.R. Kammerer. 2013a. Thermal stability of anthocyanins and colourless phenolics in pomegranate (Punica granatum L.) juices and model solutions. Food Chemistry 138:1800-1809. doi:10.1016/ j.foodchem.2012.10.072.

Fischer, U.A., A.V. Jaksch, R. Carle, and D.R. Kammerer. 2013b. Influence of origin source, different fruit tissue and juice extraction methods on anthocyanin, phenolic acid, hydrolysable tannin and isolariciresinol contents of pomegranate (Punica granatum L.) fruits and juices. European Food Research Technology 237:209-221. doi:10.1007/s00217-013-1981-2. 
Gil, M.I., R. Sánchez, J.G. Marín, and F. Artés. 1996. Quality changes in pomegranates during ripening and cold storage. Zeitschrift für Lebensmittel-Untersuchung und -Forschung. 20(6)2:481-485. doi:10.1007/BF01197269.

Gil, M.I., F.A. Tomás-Barberán, B. Hess-Pierce, D.M. Holcroft, and A.A. Kader. 2000. Antioxidant activity of pomegranate juice and its relationship with phenolic composition and processing. Journal of Agricultural and Food Chemistry 48:4581-4589. doi:10.1021/jf000404a.

Gómez-Caravaca, A.M., V. Verardo, M. Toselli, A. SeguraCarretero, A. Fernández-Gutiérrez, and M.F. Caboni. 2013. Determination of the major phenolic compounds in pomegranate juices by HPLC-DAD-ESI-MS. Journal of Agricultural and Food Chemistry 61:5328-5337. doi:10.1021/jf400684n.

Gözlekci, S., O. Saracoglu, E. Onursal, and M. Özgen. 2011. Total phenolic distribution of juice, peel, and seed extracts of four pomegranate cultivars. Pharmacognosy Magazine 7:161-164. doi:10.4103/0973-1296.80681.

Hasnaoui, N., R. Jbir, M. Mars, M. Trifi, A. Kamal-Eldin, P. Melgarejo, et al. 2011. Organic acids, sugars, and anthocyanins contents in juices of Tunisian pomegranate fruits. International Journal of Food Properties 14:741-757. doi: 10.1080/10942910903383438.

INE. 2015. Medio ambiente. Informe anual 2014. Instituto Nacional de Estadísticas (INE), Santiago, Chile. Available at http://www.ine. cl/canales/chile_estadistico/estadisticas_medio_ambiente/2014/ informe-medio-ambiente2014.pdf (accessed May 2015).

Kulkarni, A.P., and S.M. Aradhya. 2005. Chemical changes and antioxidant activity in pomegranate arils during fruit development. Food Chemistry 93:319-324. doi:10.1016/ j.foodchem.2004.09.029.

Li, X., H. Wasila, L. Liu, T. Yuan, Z. Gao, B. Zhao, et al. 2015. Physicochemical characteristics, polyphenol compositions and antioxidant potential of pomegranate juices from 10 Chinese cultivars and the environmental factors analysis. Food Chemistry 175:575-584. doi:10.1016/j.foodchem.2014.12.003.

López, F. 2014. New trends in fruit juices: superfruits. p. $27-$ 40. In Falguera, V., and A. Ibarz (eds.) Juice processing juice processing: Quality, safety and value-added opportunities. CRC Press, Boca Raton, Florida, USA.

Martínez, J.J., P. Melgarejo, F. Hernández, D.M. Salazar, and R. Martínez. 2006. Seed characterisation of five new pomegranate (Punica granatum L.) varieties. Scientia Horticulturae 110:241246. doi:10.1016/j.scienta.2006.07.018.

Mditshwa, A., O.A. Fawole, F. Al-Said, R. Al-Yahyai, and U.L. Opara. 2013. Phytochemical content, antioxidant capacity and physicochemical properties of pomegranate grown in different microclimates in South Africa. South African Journal of Plant and Soil 30:81-90. doi:10.1080/02571862.2013.802033.

Mirdehghan, S.H., and M. Rahemi. 2007. Seasonal changes of mineral nutrients and phenolics in pomegranate (Punica granatum L.) fruit. Scientia Horticulturae 111:120-127. doi:10.1016/j.scienta.2006.10.001.

Mphahlele, R.R., O.J. Caleb, O.A. Fawole, and U.L. Opara. 2016. Effects of different maturity stages and growing locations on changes in chemical, biochemical and aroma volatile composition of 'Wonderful' pomegranate juice. Journal of the Science of Food and Agriculture 96:1002-1009. doi:10.1002/jsfa.7186.

Mphahlele, R.R., M.A. Stander, O.A. Fawole, and U.L. Opara. 2014. Effect of fruit maturity and growing location on the postharvest contents of flavonoids, phenolic acids, vitamin $\mathrm{C}$ and antioxidant activity of pomegranate juice (cv. Wonderful). Scientia Horticulturae 179:36-45. doi:10.1016/j.scienta.2014.09.007.
Nuncio-Jáuregui, N., S. Munera-Picazo, Á Calín-Sánchez, A. Wojdylo, F. Hernández, and ÁA. Carbonell-Barrachina. 2015. Bioactive compound composition of pomegranate fruits removed during thinning. Journal of Food Composition and Analysis 37:11-19. doi:10.1016/j.jfca.2014.06.015.

ODEPA. 2015. Catastro frutícola, principales resultados. Oficina de Estudio y Políticas Agrarias (ODEPA), Santiago, Chile. Available at http://www.odepa.cl/wp-content/uploads/2015/09/CatastroFruticola-IV-Region-Coquimbo-2015.pdf (accessed April 2016).

Radunic, M., M. Jukic Spika, S. Goreta Ban, J. Gadze, J.C. DíazPérez, and D. MacLean. 2015. Physical and chemical properties of pomegranate fruit accessions from Croatia. Food Chemistry 177:53-60. doi:10.1016/j.foodchem.2014.12.102.

Schwartz, E., R. Tzulker, I. Glazer, I. Bar-Ya'akov, Z. Wiesman, E. Tripler, et al. 2009. Environmental conditions affect the color, taste, and antioxidant capacity of 11 pomegranate accessions fruit. Journal of Agriculture and Food Chemistry 19:9197-9204. doi:10.1021/jf901466c.

Sepúlveda, E., C. Sáenz, Á Peña, P. Robert, B. Bartolomé, and C. Gómez-Cordovés. 2010. Influence of the genotype on the anthocyanin composition, antioxidant capacity and color of Chilean pomegranate (Punica granatum L.) juices. Chilean Journal of Agricultural Research 70:50-57. doi:10.4067/S0718-58392010000100005.

Shwartz, E., I. Glazer, I. Bar-Ya'akov, I. Matityahu, I. Bar-Ilan, D. Holland, et al. 2009. Changes in chemical constituents during the maturation and ripening of two commercially important pomegranate accessions. Food Chemistry 115:965-973 doi:10.1016/j.foodchem.2009.01.036.

Supe, V.S., and Y.S. Saitwal. 2016. Morphological, biochemical and qualitative changes associated with growth andevelopment o pomegranate fruit (Punica granatum L.) Indian Journal of Agricultural and Research 50:80-83. doi:10.18805/ijare.v0iOF.7106.

Tehranifar, A., M. Zarei, Z. Nemati, B. Esfandiyari, and M.R. Vazifeshenas. 2010. Investigation of physico-chemical properties and antioxidant activity of twenty Iranian pomegranate (Punica granatum L.) cultivars. Scientia Horticulturae 126:180-185. doi:10.1016/j.scienta.2010.07.001

Teixeira da Silva, J.A., T.S. Rana, D. Narzary, N. Verma, D.T. Meshram, and S.A. Ranade. 2013. Pomegranate biology and biotechnology: a review. Scientia Horticulturae 160:85-107. doi:10.1016/j.scienta.2013.05.017.

Türkyilmaz, M. 2013. Anthocyanin and organic acid profiles of pomegranate (Punica granatum L.) juices from registered varieties in Turkey. International Journal of Food Science and Technology 48:2086-2095. doi:10.1111/ijfs.12190.

Tzulker, R., I. Glazer, I. Bar-Ilan, D. Holland, M. Aviram, and R. Amir. 2007. Antioxidant activity, polyphenol content, and related compounds in different fruit juices and homogenates prepared from 29 different pomegranate accessions. Journal of Agricultural and Food Chemistry 55:9559-9570. doi:10.1021/jf071413n.

Weerakkody, P., J. Jobling, M.M.V. Infante, and G. Rogers. 2010. The effect of maturity, sunburn and the application of sunscreens on the internal and external qualities of pomegranate fruit grown in Australia. Scientia Horticulturae 124:57-61. doi:10.1016/j.scienta.2009.12.003.

Zaouay, F., P. Mena, C. Garcia-Viguera, and M. Mars. 2012. Antioxidant activity and physico-chemical properties of Tunisian grown pomegranate (Punica granatum L.) cultivars. Industrial Crops and Products 40:81-89. doi:10.1016/j.indcrop.2012.02.045.

Zarei, M., M. Azizi, and Z. Bashir-Sadr. 2011. Evaluation of physicochemical characteristics of pomegranate (Punica granatum L.) fruit during ripening. Fruits 66:121-129. doi:10.1051/fruits/2011021 